\title{
Asian communities come to the fore of place branding: special issue on the third IPBA conference
}

\author{
Leonardo A. N. Dioko ${ }^{1}$
}

Published online: 22 October 2019

๑) Springer Nature Limited 2019

This special issue of Place Branding and Public Policy is comprised of articles curated from the third conference of the International Place Branding Association (IPBA), which took place in Macao SAR, China. Co-organized and hosted by the Destination Branding and Marketing Conference Group (DBM) at the Macao Institute for Tourism Studies, from 5 to 7 December 2018, it was the first time the IPBA conference ventured outside Europe and also the first time it was held in the Asia-Pacific region. The conference therefore gave a remarkable opportunity for a more diverse representation and background of delegates to participate and share their unique perspectives in the burgeoning global field of place branding. As each IPBA conference has done annually since its first meeting in London in 2016, the Macao conference also provided a valuable occasion to survey the latest thoughts, issues, and research advances in the field. Though a relative newcomer in the international conference calendar, what many don't realize is that the IPBA Conference is the fusion of several diverse streams of communities and ideas that have for many years independently orbited the central notion of place branding along different paths. The IPBA's inception thus brings all these streams together, if not closer, into a single flow.

As Nobel prize winner Linus Pauling once aptly said: "The best way to have a good idea is to have lots of ideas." In this regard, the third IPBA Conference did not disappoint. As well as attracting its loyal and eminent cadre of scholars and practitioners in place branding, the conference also had the notable involvement of several first-time delegates from nearby countries in the Asia-Pacific region and from diverse fields of study, thus officially 'globalizing' and bridging a movement which originally began as regional initiatives, such as the International Colloquia on Place Brand Management (London) in 2009, the City Branding Symposia

Leonardo A. N. Dioko

Don@ift.edu.mo

1 Macao Institute for Tourism Studies (IFT), Macao, China
(Stockholm in 2012 and Beijing in 2013), the Poznan Best Place Summit in 2014, and the Destination Branding and Marketing Conference Series, which began in Macao in 2005 and is one of the longest running conference series in the wider place branding field. In this light, Rich Harrill (University of South Carolina HRSM) and Nigel Morgan (University of Surrey), both co-founders of the DBM Conference, emphatically declared: "Whereas you might have a rather diverse group of scholars and practitioners studying a narrowly conceived subject, or, conversely, a well-defined group of scholars and practitioners studying a wide variety of related topics, the DBM Conference (which now partners with the IPBA), has remained an intact community, or even a family, of faculty, students, practitioners, and interested observers that are passionate about how the best places and destinations are built and function, and marketed and branded."

This special issue does not purport to be representative of all the remarkable presentations and ideas at the Macao conference. Neither does it strive to impossibly condense the multiverse of ideas rapidly evolving in the field nor attempt to summarize the latest developments. Rather, it aims to showcase some of the noteworthy research and efforts taking place and how these are emerging from unconventional origins, backgrounds, and produced by multifaceted groups of engaged individuals coming from different fields of study.

Of the seven articles in this compilation, five were authored or co-authored by Asians or deal with place branding in an Asian setting. Several of the articles echo universal themes long associated with place branding issues. For example, Viriya Taecharungroj and his co-authors' article, Sustainability as a place brand position: A resident-centric analysis of the ten towns in the vicinity of Bangkok, advocate a more holistic branding process that puts local communities at the heart of initiatives. Studying a cluster of small towns and villages in and around the Bangkok area, their findings unveil several unique place branding values only the locally bounded and well-grounded scale of their observations 
could reveal. Towns and villages, the article cites, might not only strive to be green but also to be compassionate, peaceful, lively, and elegant in their branding development and positioning.

Considering the growing and ever more divergent gulf between local communities and the pervasive onslaught of tourism, Beatriz Casais and Patricia Monteiro's study on Residents' involvement in city brand co-creation and their perceptions of city brand identity: A case study in Porto resonates strongly in a world increasingly subject to intense and disruptive tourism growth. In the study, Casais and Monteiro detail a case branding exercise undertaken by the historic Portuguese city of Porte to develop a new brand identity. However good and noble the intent, the authors still lament how the process often ignores the co-creative power of the city's residents especially in infusing brand development efforts with much needed authenticity and sense of place.

This special issue includes two articles addressing nation branding, media perceptions, image building, and public diplomacy. In National stereotype effects on high versus lowcontact service expectations: Branding Indonesia, Michael Chattalas and his co-authors examine how extant cultural stereotypes associated with certain nation brands, such as perceived warmth and competence, could provide advantageous outcomes when employed appropriately as part of promoting nation brands and services. Such thoughtful insights helped garner the article the AJ Hackett Best Paper Award at the conference in Macao. In another article on How vlogging promotes a destination image: A narrative analysis of popular travel vlogs about the Philippines, Rachel Luna Peralta critically reveals how established video bloggers-often not in any way rooted or connected in a local community—can wield significant influence not only in shaping nation image but also in solidifying place identity through highly personalized multimedia storytelling and representation.

Place branding has always been the go-to field for communities seeking ways to reinforce their well-earned brand identities or protect their brand from the vagaries of sociopolitical and economic tides. Along this vein, Chunying Wen and her co-authors submit that advertising remains a highly effective communications platform, despite the surrounding hype and (overstated) benefits of non-traditional forms of media. In their study, Measuring the economic effectiveness of place advertising in China, they examined place brand advertising campaigns mounted by 31 provinces in China across a 10-year period and found a clear and significant positive link between ad spending and visitor spending. The rigor, breadth, and depth of the study's data were recognized when the study received the IFT Best Paper Award.

But a return to traditional advertising strategies for place branding can be rendered ineffective if the underlying community's strengths are ignored. In this light, Sylwia DudekMańkowska and Miroslaw Grochowski maintain how often cities overlook their latent creative potential in building their brand identities. In their article, From creative industries to the creative place brand: some reflections on city branding in Poland, the authors reveal how regional capital cities in Poland possess significant creative potential but remains largely untapped despite the search many cities pursue to find a distinctive and unique image or identity. In effect, the authors advocate unleashing the creative powers lying inherently within cities in developing their place brands, rather than relying solely on well-worn strategic branding notions and templates.

Finally, Stephen Poon's article on Reimagining the place and placelessness: Heritage symbolism and hospitality architectural designs might strike readers as being out of place-but the piece is anything but. In dissecting and contrasting a couple of architectural styles found in modern hotel designs, Poon reflects how efforts to incorporate local heritage, symbolisms, and vernacular designs, though grounded on benevolent and respectful intent, ultimately and often unintendedly produces a state of placelessness especially when the traditions and meanings which produce such heritage elements are ignored, thereby 'decontextualizing' and fusing them within modern manifestations of hospitality facilities. The untoward result is reductionism and subversion of community sense of place. For the unconventional perspectives the article advances, the paper was accorded the IPBA Best Paper Award.

\section{Quo vadis place branding?}

The hope of every special interest conference or journal special issue is that it impels contributing authors to push the boundaries of the field, to provoke and prompt the advancement of unconventional ideas and advocacies that might eventually enrich both practice and thought. The contributors of this special issue arguably have, in some small measure, aided us toward this goal. As the International Place Branding Association continues to advance its work, be it through its annual conference or through special thematic compilations such as this, the burden of such a lofty aim remains urgent and imposing.

Because they straddle a vast panoply of conceptual ground, research on place branding and public diplomacy risk getting endlessly adrift or in directional limbo. Many studies that inform the place branding discourse originate from domains as disparate as marketing, public administration, tourism, events, governance, and economics. Unless future studies posit more transcendent, novel, and genuinely ground-breaking concepts, the field can perilously stagnate within a dense conceptual fog. Perhaps recent concepts such as the one advanced by Robert Govers, the Founding Chair of the IPBA, in which he extols imaginative communities, 
provide one such needed boost. But the need and search for more must continue.

Publisher's Note Springer Nature remains neutral with regard to jurisdictional claims in published maps and institutional affiliations.

Leonardo A. N. Dioko Phd., is Professor at the Macao Institute for Tourism Studies (IFT), where he teaches courses in tourism and hospitality marketing and management. Concurrently, he is Director of IFT's
Tourism Research Centre (ITRC), which conducts policy research on Macao's tourism development, some of which are commissioned by the Macau S.A.R. Government, and center on destination or tourism carrying capacity. Don's research interest includes, inter alia, destination branding and marketing, the shaping and evaluation of tourism policy, and knowledge disparities between tourism theory building and applications. 